\title{
A simple and efficient asymmetric synthesis of 3-alkyl-isoindolin-1-ones
}

\author{
Joëlle Pérard-Viret, ${ }^{\mathrm{a}}$ Thierry Prangé, ${ }^{\mathrm{b}}$ Alain Tomas ${ }^{\mathrm{b}}$ and Jacques Royer ${ }^{\mathrm{a}, *}$ \\ a'Laboratoire de Chimie Thérapeutique, Faculté de Pharmacie, UMR 8638 CNRS/Université René Descartes, \\ 4 avenue de l'Observatoire, 75270 Paris Cedex 06, France \\ ${ }^{\mathrm{b}}$ Laboratoire de Cristallographie, Faculté de Pharmacie, UMR 8015 CNRS/Université René Descartes, \\ 4 avenue de l'Observatoire, 75006 Paris Cedex, France
}

Dedicated to the memory of André Collet, who introduced me to chirality (J. P.-V.)

\begin{abstract}
A simple asymmetric access to 3-alkyl-isoindolin-1-ones was investigated through the diastereoselective alkylation of 2-[(1R)-2hydroxy-1-phenylethyl]-2,3-dihydro- $1 H$-isoindolin-1-one 5. High diastereoselectivities were observed with LDA or LiHMDS while the isolated yields were modest (about 50\%). In contrast the use of NaHMDS gave good isolated yields (up to 85\%) but lowered diastereoselectivities. This methodology offers an efficient asymmetric synthesis of 3-alkylated isoindolin-1-ones.
\end{abstract}

Numerous synthetic and natural products possessing the 3-alkyl-isoindolin-1-one substructure were described. The compounds isolated from natural sources possess more or less complex structures ${ }^{1}$ as for example indolocarbazoles $\mathbf{1}$ (staurosporine $^{2}$ and derivatives) or tetrahydro-isoindolobenzazepines (lennoxamine (2)). ${ }^{3}$ On the other hand, synthetic 3-substituted isoindolin-1-ones were studied as anxiolytics (pazinaclone $(3)),{ }^{4} 5-\mathrm{HT}_{1 \mathrm{~A}}$ antagonists, ${ }^{5}$ reverse transcriptase inhibitors, ${ }^{6}$ or vasodilatators. ${ }^{7}$ More generally, the easily metabolised benzylic alcohol can be replaced by the bioisosteric isoindolinone. ${ }^{8}$

Several synthetic pathways were known to synthesize 3-alkyl-isoindolin-1-ones. ${ }^{9}$ Indeed a limited number of methods towards the preparation of the heterocyclic skeleton were reported and only very recent works were devoted to develop a general synthetic strategy mainly through the alkylation of isoindolinones at C-3 (Fig. 1).

This alkylation was described using both carbanionic ${ }^{10}$ and carbocationic $^{11}$ strategies. Carbanionic methods may utilise a stabilizing group, ${ }^{10 a}$ that was introduced at the carbon ipso. Quite recently, the group of A. Couture ${ }^{10 b}$ was the first to propose the substitution of isoindolinones through the formation of an unstabilized carbanion. This very simple method was used with success by Guo, ${ }^{10 c}$ but was not found to be generally applicable by Enders ${ }^{10 \mathrm{~d}}$ in the case

Keywords: isoindolin-1-one; alkylation; carbanions; $(R)$-phenylglycinol; amide bases.

${ }^{*}$ Corresponding author. Tel.: +33-1-537-397-49; fax: +33-1-432-914-03; e-mail: jacques.royer@pharmacie.univ-paris5.fr of $N$-dimethyl amino isoindolinones. This latter author used benzotriazole stabilized carbanion as an efficient but multistep methodology. The carbocationic approach was reported in some instances ${ }^{11}$ from which the work developed by Allin et al. ${ }^{11 \mathrm{a}, \mathrm{b}}$ constitutes the unique asymmetric synthesis of 3-alkyl-isoindolin-1-ones. Modest to good diastereoselectivities were obtained by Allin and co-workers.

We became interested to try and propose a new and asymmetric approach since we anticipated that an asymmetric version of the unstabilized carbanion method could be developed using isoindolidinone bearing a chiral appendage

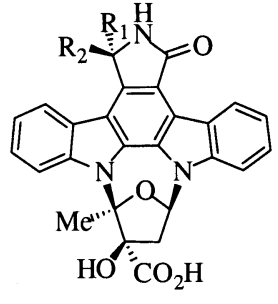

1

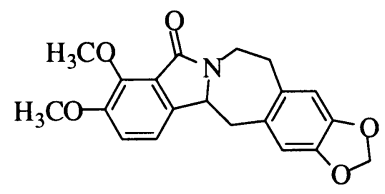

2

Figure 1. 
<smiles>COC1C=CC(OC)O1</smiles>

Scheme 1.

at nitrogen atom. This was inspired from a methodology we developed for some years on chiral $\gamma$-lactam. ${ }^{12}$ This method was based on the preparation of the chiral non-racemic $\gamma$-lactam 4 in a single step from dimethoxydihydrofuran and a chiral amine, followed by the asymmetric alkylation of this chiral lactam (Scheme 1). For this alkylation step, it was necessary to use a chiral appendage bearing a free alcohol function able to strongly coordinate the lithium enolate: $^{12}$ then the use of $(R)$-phenylglycinol as the starting chiral amine was found to be essential in order to get high diastereomeric excesses.

This paper will present the asymmetric alkylation of 2-[(1R)-2-hydroxy-1 phenylethyl]-2,3-dihydro- $1 H$-isoindol1-one 5 through the formation of an unstabilized carbanion.

\section{Results and discussion}

The preparation of $\mathbf{5}$ was envisaged through the condensation of the primary amine function of $(R)$-phenylglycinol with phthalic dialdehyde following the condensation method discovered in 1909 by Thiele. ${ }^{13}$ This method was widely used for the preparation of isoindolinone skeleton but claimed to give modest or low yields with some primary amines and several modifications were proposed giving improvement in specific cases. ${ }^{9,14}$

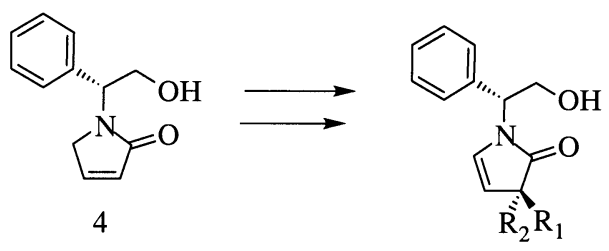

In our hands, the treatment of a 1/1 mixture of $(R)$-phenylglycinol and phthalic dialdehyde in isopropanol and in the presence of $\mathrm{HCl}$ gave the isoindolinone 5 in $52 \%$ yield after purification (Scheme 2). Despite the modest yield, we found this method convenient for our purpose, since it is a very simple one-step reaction. Indeed, the isoindolinone $\mathbf{5}$ is a known product prepared through the condensation of phenylglycinol and 2-formylbenzoic acid, followed by reduction ( $59 \%$ overall yield). ${ }^{15}$

With isoindolinone $\mathbf{5}$ in hand, we considered its alkylation through the formation of carbanion. In the first attempt we chose to use LDA following the procedure described by Couture. ${ }^{10 \mathrm{~b}}$ The deprotonation was conducted at $-78^{\circ} \mathrm{C}$, using 2.2 equiv. of base in THF and the so-formed carbanion was trapped with methyl iodide to give the 3-methyl isoindolinone 6a (Scheme 2) in $40 \%$ yield along with the starting material that was recovered in about $40 \%$ yield. This alkylation was proved to be highly diastereoselective: compound $\mathbf{6 a}$ was isolated as a unique diastereomer. Careful examination of the ${ }^{1} \mathrm{H}$ and ${ }^{13} \mathrm{C}$ NMR spectra of the crude reaction mixture revealed the presence of less than $5 \%$ of epimeric material. Further studies were undertaken in order to improve the yield of this very simple process by varying mainly the nature of the base and the nature of the metal. Methyl, propyl, allyl and benzyl halides were used in this study. All the reactions were conducted under the above

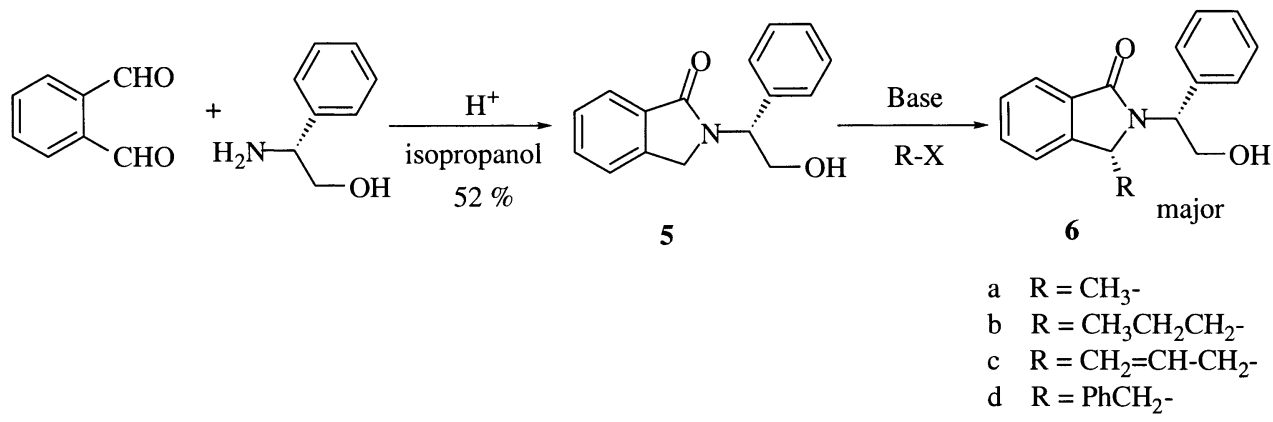

Scheme 2.

Table 1. Yield and diastereoselectivity in the alkylation of $\mathbf{5}\left(\mathrm{THF},-78^{\circ} \mathrm{C}\right)$ with different primary alkyl halides $(1.2$ equiv.) and with different bases (2.2 equiv.)

\begin{tabular}{|c|c|c|c|c|c|c|c|c|}
\hline \multirow{2}{*}{$\begin{array}{l}\text { Base-> } \\
\text { Electrophile }\end{array}$} & \multicolumn{2}{|c|}{ LDA } & \multicolumn{2}{|c|}{ LiHMDS } & \multicolumn{2}{|c|}{ NaHMDS } & \multicolumn{2}{|c|}{ KHMDS } \\
\hline & Yield $^{\mathrm{a}}(\%)$ & $\mathrm{dr}^{\mathrm{b}}(\%)$ & Yield $^{\mathrm{a}}(\%)$ & $\mathrm{dr}^{\mathrm{b}}(\%)$ & Yield $^{\mathrm{a}}(\%)$ & $\mathrm{dr}^{\mathrm{b}}(\%)$ & Yield $^{\mathrm{a}}$ & $\mathrm{dr}^{\mathrm{b}}$ \\
\hline MeI & 40 & $95: 5$ & 32 & $95: 5$ & 71 & $74: 26$ & 60 & $53: 47$ \\
\hline $\mathrm{PrBr}$ & 41 & $\approx 95: 5$ & - & - & 72 & $96: 4$ & 63 & $96: 4$ \\
\hline $\mathrm{AllBr}$ & - & - & 39 & $>95: 5$ & 41 & $50: 50$ & 53 & $50: 50$ \\
\hline $\mathrm{BnBr}$ & 37 & $95: 5$ & 28 & $>95: 5$ & 80 & $50: 50$ & - & - \\
\hline $\mathrm{BnCl}$ & - & - & - & - & 25 & $>95: 5$ & 50 & $66: 34$ \\
\hline
\end{tabular}

a Yield of isolated alkylated product.

${ }^{\mathrm{b}}$ Diastereoselective ratio for the crude reaction mixture. 

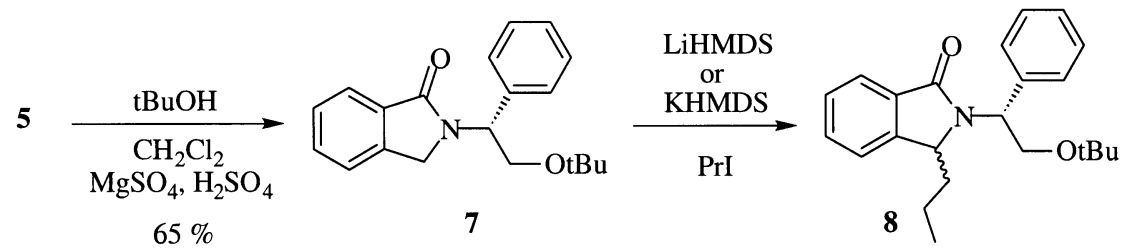

Scheme 3.

conditions. From Table 1 it can be seen that excellent diastereoselection was obtained with all the alkyl halides used when the base was LDA or LiHMDS. Unfortunately, in each case, the yield was always modest and less than $50 \%$. Using a large excess (10 equiv.) of halide did not give any improvement. Raising the temperature up to $\mathrm{rt}$ or using large excess of base were without effect upon the yield of the reaction, and about $40 \%$ of starting material were recovered. It must be noticed that, even in this large excess procedure, no bis-alkylated product was obtained.

We eventually obtained an improved alkylation yield by changing the counterion of the base. The use of NaHMDS gave the alkylation products $\mathbf{6} \mathbf{a}-\mathbf{d}$ in yields improved up to $80 \%$. Unfortunately, in these cases, the diastereoselectivity was dramatically lowered, mainly for the more electrophilic compounds: benzyl and allyl bromides. In order to confirm this assumption, we tried an alkylation reaction with benzyl chloride: if NaHMDS was used as base, the yield was low $(25 \%)$ but the diastereoselectivity excellent, while KHMDS underwent an acceptable 50\% yield and a low dr In most cases deprotonation with KHMDS gave worse diastereoselectivity. These different diastereoselectivities observed through the use of different bases suggested the formation of a chelated intermediate. The chelation would be better with lithium than with sodium or potassium.

Nevertheless, the results obtained with propyl bromide were particularly astonishing since they did not follow the same tendency.

An another proof for an intramolecular chelation was given by the experiments we conducted with the $O$-tert-butyl

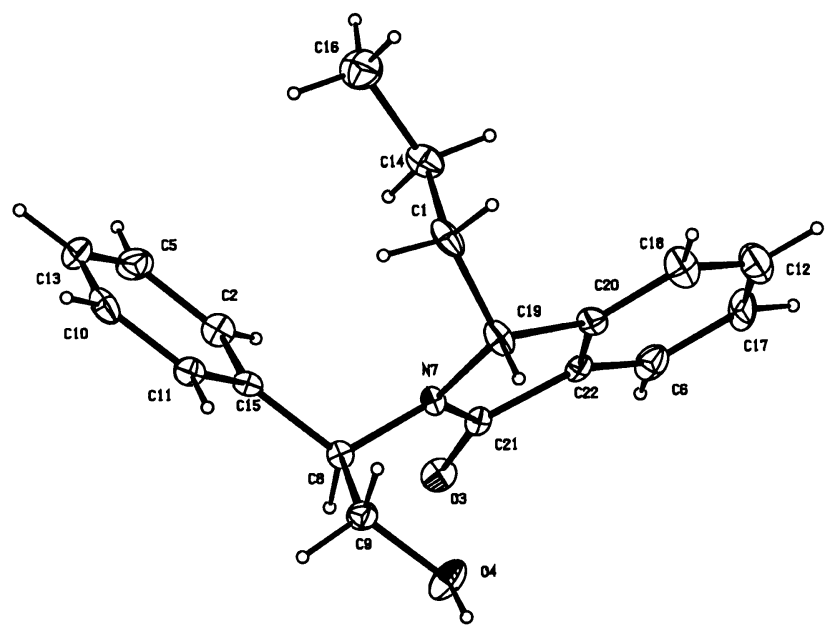

Figure 2. derivative 7 (prepared from 5 in $65 \%$ yield, Scheme 3). Using LiHMDS as base, compound 7 was alkylated with propyl iodide to give $\mathbf{8}$ ( $85 \%$ yield) with only $74: 26 \mathrm{dr}$ (the diastereomeric ratio was lowered to $69: 31$ by the use of KHMDS as base).

A $3 R$ configuration was determined for compound $\mathbf{6 b}$ through an X-ray analysis of suitable crystals. The ORTEP representation is given in Fig. 2. The same configuration was expected for all alkyl compounds $\mathbf{6}$ obtained through the deprotonation of $\mathbf{5}$ by LDA or LiHMDS.

Furthermore, this was confirmed for compound $\mathbf{6 c},{ }^{16}$ since its hydrogenation $\left(\mathrm{H}_{2}, \mathrm{Pd} / \mathrm{C}\right.$ in $\left.\mathrm{MeOH}\right)$ gave, in $95 \%$ yield, the propyl derivative identical in all aspects with $\mathbf{6 b}$. The different experimental results obtained along this work clearly proved the existence of an intramolecular chelation. The configuration of the newly formed chiral centre was consistent with two possible models for the carbanionic species depicted in Fig. 3. In model (A), we assumed a configurationally stable anion which is stabilised through a intramolecular chelation by the alcoholate. The expected chair like conformation and the retention of configuration would lead to the observed $3 R$ configuration. In the enolate model (B), an intramolecular chelation is also expected and the attack of the electrophile from the less sterically hindered face (anti to the phenyl group) would also provide the $3 R$ alkylated derivative.

At this stage we have no experimental evidence to support either model A or B, however further work is underway to elucidate the most favorable conformation.

In conclusion we developed a rapid and efficient process for the asymmetric synthesis of 3-alkyl-isoindolinones. Excellent diastereoselectivities were obtained and render the process particularly efficient despite the modest yield. Cleavage of the chiral appendage in this 2-hydroxy-1phenylethyl isoindolinone series was reported by Fains et al. ${ }^{15}$ and by Allin ${ }^{11 b}$ to occur in good yield and without loss of stereochemical integrity.
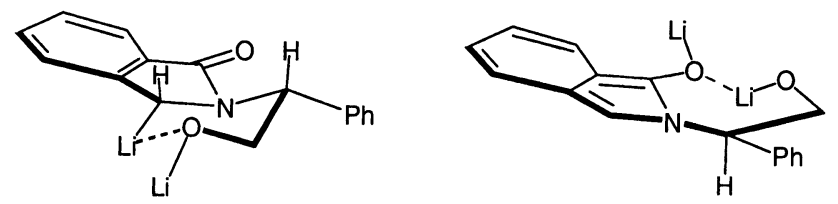

$\mathbf{B}$

Figure 3. 


\section{Experimental}

\subsection{General}

All solvents were dried by standard methods. Melting points were determined on a Leica melting point microscope and are uncorrected. IR spectra were obtained using a Nicolet 205-FT infrared spectrophotometer. Only noteworthy IR absorptions are listed $\left(\mathrm{cm}^{-1}\right) .{ }^{1} \mathrm{H}$ and ${ }^{13} \mathrm{C}$ NMR spectra $(\delta$ (ppm), $J$ (Hertz)), solvent $\mathrm{CDCl}_{3}$ ) were recorded with a Bruker AC-300 (300 and $75.5 \mathrm{MHz}$ ) instrument. Elementary analyses were performed at the Microanalysis Laboratory of the Pierre et Marie Curie University (Paris). Mass spectra were recorded with a Nermag R10-10C instrument. HRMS: Micromass LCT (positive Electrospray mode with internal standard 'lock-mass'). Optical rotations were measured with a Perkin-Elmer 241 polarimeter. Analytical TLC was carried out using aluminum-backed plates coated with $0.2 \mathrm{~mm}$ silica gel $60 \mathrm{~F}_{254}$, Merck. Preparative flashcolumn chromatography was carried out using SDS silica gel $60(35-70 \mu \mathrm{m})$.

\subsubsection{2-[(1R)-2-Hydroxy-1phenylethyl]-2,3-dihydro-1H-} isoindol-1-one (5). A solution of $(R)$-phenylglycinol $(5 \mathrm{~g}$, $36 \mathrm{mmol}$ ) in $150 \mathrm{~mL}$ of water and $47.2 \mathrm{~mL}$ of $\mathrm{HCl} 1 \mathrm{~N}$ was added dropwise to a solution of 1,2-phthalic dicarboxaldehyde $(4.8 \mathrm{~g}, 36 \mathrm{mmol})$ in 2-propanol $(20 \mathrm{~mL})$ at room temperature. The solution was stirred for $4 \mathrm{~h}$, and then made alkaline with solid sodium hydrogenocarbonate, and extracted with dichloromethane. The extracts were combined, dried over magnesium sulfate and evaporated under vacuum. The oily residue was purified by precipitation with a mixture of diethyl ether and a small quantity of dichloromethane, filtration gave $1.7 \mathrm{~g}(18.7 \%)$ of a slightly yellow powder. The filtrate was evaporated and purified by flash column chromatography on $\mathrm{SiO}_{2}$ using $\mathrm{CH}_{2} \mathrm{Cl}_{2} / \mathrm{MeOH}(97.5: 2.5)$ as eluent to afford $3.1 \mathrm{~g}(34 \%)$ of 5 (total yield $52 \%$ ).

$\operatorname{Mp~} 115^{\circ} \mathrm{C} ;[\alpha]_{\mathrm{D}}=-19\left(c=0.6, \mathrm{CH}_{2} \mathrm{Cl}_{2}\right) ;{ }^{1} \mathrm{H} \operatorname{NMR} \delta 3.84(\mathrm{t}$, $J=6.25 \mathrm{~Hz}, 1 \mathrm{H}), 4.12(\mathrm{~d}, J=17.1 \mathrm{~Hz}, 1 \mathrm{H}), 4.15(\mathrm{~m}, 1 \mathrm{H})$, $4.42(\mathrm{~d}, 17.1 \mathrm{~Hz}, 1 \mathrm{H}), 5.32$ (dd, $J=8.48,4.64 \mathrm{~Hz}, 1 \mathrm{H})$, $7.2-7.5(\mathrm{~m}, 8 \mathrm{H}), 7.8(\mathrm{~d}, J=7.4 \mathrm{~Hz}, 1 \mathrm{H}) ;{ }^{13} \mathrm{C} \mathrm{NMR} \delta 48.5$ $\left(1 \mathrm{CH}_{2}\right), 59.3(1 \mathrm{CH}), 63.0\left(1 \mathrm{CH}_{2}\right), 122.5,123.6,127.4$, $127.8,127.9,128.8,131.3(7 \mathrm{CH}), 132.4,137.4,141.4$ (3C), 169.7 (CO); IR (nujol) 3440, 1664, 1455, 1213, 1070, 696; Anal. calcd for $\mathrm{C}_{16} \mathrm{H}_{15} \mathrm{NO}_{2}$ : C, 75.87; H, 5.97; N, 5.53. Found: C, 75.27; H, 5.89; N, 5.27; $\mathrm{m} / \mathrm{z}$ (CI) 254 $\left[\mathrm{MH}^{+}, 100 \%\right]$.

\subsection{General procedure for the alkylation of 5}

Isoindolinone 5 (126 mg, $0.5 \mathrm{mmol})$ was dissolved in anhydrous THF (10 mL) under argon, cooled in a dry ice-acetone bath; then a solution of base $(1.1 \mathrm{mmol})$ was added dropwise. After $20 \mathrm{~min}$, the mixture was treated with the appropriate alkyl halide (1.2-4 equiv.), stirred for $2 \mathrm{~h}$ at $-78^{\circ} \mathrm{C}$. The reaction was quenched by $2 \mathrm{~mL}$ of saturated aqueous $\mathrm{NH}_{4} \mathrm{Cl}$ solution, water was added and the crude product was extracted with $\mathrm{CH}_{2} \mathrm{Cl}_{2}$, dried over magnesium sulfate, filtered and evaporated under reduced pressure. The residue was purified by flash column chromatography on $\mathrm{SiO}_{2}$ using $\mathrm{CH}_{2} \mathrm{Cl}_{2} / \mathrm{MeOH}(97.5: 2.5)$ as eluent.
2.2.1. (3R)-Methyl-2-[(1R)-2-hydroxy-1phenylethyl]-2,3dihydro-1 $H$-isoindol-1-one (6a). Oil; $[\alpha]_{\mathrm{D}}=+84(c=0.9$, $\mathrm{CH}_{2} \mathrm{Cl}_{2}$ ) (lit. $\left.{ }^{11 \mathrm{~b}}+21.3, c=2.34, \mathrm{CH}_{2} \mathrm{Cl}_{2}\right) ;\left({ }^{1} \mathrm{H}\right.$ NMR $\delta 1.44$ (d, $J=6.6 \mathrm{~Hz}, 3 \mathrm{H}), 4.1$ (ddd, $J=15.75,6,3.6 \mathrm{~Hz}, 1 \mathrm{H}), 4.35$ (q, $J=6.6 \mathrm{~Hz}), 4.48$ (ddd, $J=15,7.5,6.5 \mathrm{~Hz}, 1 \mathrm{H}), 4.78$ (dd, $J=8,3.5 \mathrm{~Hz}, 1 \mathrm{H}), 4.90(\mathrm{t}, J=6.9 \mathrm{~Hz}, 1 \mathrm{H}(\mathrm{OH})), 7.26-7.35$ $(\mathrm{m}, 6 \mathrm{H}), 7.45-7.57(\mathrm{~m}, 2 \mathrm{H}), 7.87(\mathrm{~d}, J=7.45 \mathrm{~Hz}, 1 \mathrm{H}) ;{ }^{13} \mathrm{C}$ NMR $\delta 18.3\left(1 \mathrm{CH}_{3}\right), 56.9,62.2(2 \mathrm{CH}), 64.5\left(1 \mathrm{CH}_{2}\right), 121.9$, $123.7,127.2,127.9,128.2,128.8,131.9(7 \mathrm{CH}), 131.9$, 137.9, 147.0 (3C), 167.0 (CO); IR (neat) 3387, 1665, 1414, 1071, 697; Found: $\mathrm{MH}^{+}, 268.1337, \mathrm{C}_{17} \mathrm{H}_{18} \mathrm{NO}_{2}$ requires 268.1338 .

2.2.2. (3R)-Proyl-2-[(1R)-2-hydroxy-1phenylethyl]-2,3dihydro-1H-isoindol-1-one (6b). $\mathrm{Mp} 143^{\circ} \mathrm{C}$; $[\alpha]_{\mathrm{D}}=+70$ $\left(c=1.5, \mathrm{CH}_{2} \mathrm{Cl}_{2}\right) ;{ }^{1} \mathrm{H}$ NMR $\delta 0.80(\mathrm{~m}, 4 \mathrm{H}), 1.1-1.23(\mathrm{~m}$, $1 \mathrm{H}), 1.86-2.05(\mathrm{~m}, 2 \mathrm{H}), 4.1$ (ddd, $J=3.3,7.0,12.2 \mathrm{~Hz}, 1 \mathrm{H})$, $4.37(\mathrm{dd}, J=3.0,5.0 \mathrm{~Hz}, 1 \mathrm{H}), 4.44$ (ddd, $J=7.8,12.4$, $7.8 \mathrm{~Hz}), 4.66(\mathrm{dd}, J=3.3,8.0 \mathrm{~Hz}, 1 \mathrm{H}), 5.00(\mathrm{t}, J=7.4 \mathrm{~Hz}$, $1 \mathrm{H}(\mathrm{OH})), 7.24-7.36(\mathrm{~m}, 6 \mathrm{H}), 7.45-7.57(\mathrm{~m}, 2 \mathrm{H}), 7.87(\mathrm{~d}$, $J=7.25 \mathrm{~Hz}, 1 \mathrm{H}),{ }^{13} \mathrm{C}$ NMR $\delta 13.8\left(1 \mathrm{CH}_{3}\right), 15,32.2\left(2 \mathrm{CH}_{2}\right)$, $60.4,61.6(2 \mathrm{CH}), 64.0\left(1 \mathrm{CH}_{2}\right), 121.8,123.5,127.1,127.8$, 128.0, 128.7, 131.7 (7CH), 132.4, 137.8, 145.3 (3C), 170.1 (CO); IR (nujol) 3300, 1660, 1415, 1076, 701; Anal. calcd for $\mathrm{C}_{19} \mathrm{H}_{21} \mathrm{NO}_{2}$ : C, 77.26; H, 7.17; N, 4.74. Found: C, 76.7; H, 7.31; N, 4.49; m/z (CI) $296\left[\mathrm{MH}^{+}, 100 \%\right]$.

\subsection{X-Ray crystallography}

$\mathrm{C}_{19} \mathrm{H}_{21} \mathrm{NO}_{2}$. Orthorhombic, space group $P 2_{1} 2_{1} 2_{1} ; a=9.203$ (1), $b=11.391$ (2), $c=9.420$ (2) $\AA, V=1601.4$ (2) $\AA^{3} ; Z=4$; $M=295.37 \mathrm{~g} ; \quad D_{\mathrm{c}}=1.225 \mathrm{~g} \mathrm{~cm}^{-3} ;$ absorption coefficient $0.079 \mathrm{~mm}^{-1} ; F(000)=632$.

The crystal dimensions $(0.03 \mathrm{~mm} \times 0.10 \mathrm{~mm} \times 0.04 \mathrm{~mm})$ being too small, diffraction data were recorded using the LURE Synchrotron facility in Orsay (France). Diffraction data were collected at wavelenth of $0.964 \AA$ using a $345 \mathrm{~mm}$ diameter MAR Research Image Plate system connected to the W32 beam line; distance crystal-detector $=110 \mathrm{~mm}$, total rotation $\omega=316^{\circ}$. A total of 4241 reflections with a resolution range 5.2-1.03 $\AA$ were measured. This set was processed using the $h k l$ suite of programs. ${ }^{17}$ This led to 785 independent reflections with $I>2 \sigma(I), R_{\text {sym }}=5.7 \%$. They were kept in the refinement calculations.

The structure was solved by direct methods using SHELXS97. ${ }^{18}$ Refinement, based on $F^{2}$, was carried out by full matrix least squares with SHELXL-97 ${ }^{19}$ software. An ORTEP ${ }^{20}$ diagram is given in Fig. 2. Non-hydrogen atoms were refined anisotropically. Hydrogen atoms were positioned geometrically and refined riding on their carrier atom with isotropic thermal displacement parameters fixed at 1.2 times those of their parent atoms. Convergence was reached at $R_{\mathrm{w}}=0.034$ for 785 reflections $\left(I>2 \sigma(I), R_{\mathrm{w} 2}=0.092\right.$ for all data and $S=1.165$ for 262 parameters. The residual electron density in the final difference Fourrer does not show

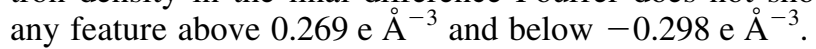

Lists of the fractional atomic coordinates, thermal parameters and bond distances and angles have been deposited with Cambridge Crystallographic Data Centre, UK as Supporting Information (CCDC reference number 176074). 
2.3.1. (3R)-Allyl-2-[(1R)-2-hydroxy-1phenylethyl]-2,3dihydro-1H-isoindol-1-one (6c). $\mathrm{Mp} 122.5^{\circ} \mathrm{C}$ (lit. ${ }^{1 \mathrm{~b}} 112$ $\left.114^{\circ} \mathrm{C}\right) ; \quad[\alpha]_{\mathrm{D}}=+111 \quad\left(c=0.5, \mathrm{CH}_{2} \mathrm{Cl}_{2}\right) \quad$ (lit. ${ }^{11 \mathrm{~b}}+152.2$, $\left.c=2.68, \mathrm{CH}_{2} \mathrm{Cl}_{2}\right) ;{ }^{1} \mathrm{H}$ NMR $\delta 2.7(\mathrm{~m}, 2 \mathrm{H}), 4.12$ (ddd, $J=12.2,5.9,3.2 \mathrm{~Hz}, 1 \mathrm{H}), 4.37-4.5(\mathrm{~m}, 2 \mathrm{H}), 4.73(\mathrm{dd}$, $J=7.7,3.2 \mathrm{~Hz}, 1 \mathrm{H}), 4.9-5.1(\mathrm{~m}, 2 \mathrm{H}), 5.3$ (dddd, $J=17.0$, 10.0, 7.7, 7.7 Hz, 1H), 7.35-7.4 (m, 6H), 7.45-7.6 (m, 2H), $7.87(\mathrm{~d}, J=7.1,1 \mathrm{H}) ;{ }^{13} \mathrm{C}$ NMR $\delta 35.0\left(1 \mathrm{CH}_{2}\right), 60.6,62.7$ $(2 \mathrm{CH}), 64.6\left(1 \mathrm{CH}_{2}\right), 119.7,122.2,123.8,127.2,128.0$, $128.3,128.8,130.4,131.8\left(8 \mathrm{CH}, 1 \mathrm{CH}_{2}\right), 132.3,137.8$, 144.8 (3C), 170.1 (CO); IR (nujol) 3379, 1647, 1453, 1059,$692 ; \mathrm{m} / z$ (CI) $294\left[\mathrm{MH}^{+}, 100 \%\right]$.

2.3.2. (3R)-Benzyl-2-[(1R)-2-hydroxy-1phenylethyl]-2,3dihydro- $1 \mathrm{H}$-isoindol-1-one $(\mathbf{6 d}) . \mathrm{Mp} 167^{\circ} \mathrm{C} ;[\alpha]_{\mathrm{D}}=+66$ $\left(c=0.5, \mathrm{CH}_{2} \mathrm{Cl}_{2}\right) ;{ }^{1} \mathrm{H}$ NMR $\delta 2.89(\mathrm{dd}, J=13.9,7.8 \mathrm{~Hz}, 1$ H), $3.36(\mathrm{dd}, J=13.9,4.4 \mathrm{~Hz}, 1 \mathrm{H}), 4.1$ (ddd, $J=12.4,7.2$, $3.4 \mathrm{~Hz}, 1 \mathrm{H}), 4.45(\mathrm{dt}, J=12.5,7.8 \mathrm{~Hz}, 1 \mathrm{H}), 4.55(\mathrm{dd}$, $J=7.8,4.4 \mathrm{~Hz}, 1 \mathrm{H}), 4.88(\mathrm{dd}, J=7.9,3.35 \mathrm{~Hz}, 1 \mathrm{H}), 5.00$ $(\mathrm{t}, J=7.35 \mathrm{~Hz}, 1 \mathrm{H}(\mathrm{OH})), 6.85(\mathrm{~m}, 1 \mathrm{H}), 6.94(\mathrm{~m}, 2 \mathrm{H})$, 7.19-7.25 (m, 5H), 7.29-7.36 (m, 3H), $7.42(\mathrm{~m}, 2 \mathrm{H}), 7.80$ $(\mathrm{m}, 1 \mathrm{H}) ;{ }^{13} \mathrm{C}$ NMR $\delta 38.1\left(1 \mathrm{CH}_{2}\right), 61.8,63.1(2 \mathrm{CH}), 64.6$ $\left(1 \mathrm{CH}_{2}\right), 122.6,123.8,127.1,127.2,128.0,128.3,128.4$, $128.9,129.4,121.4(10 \mathrm{CH}), 132.1,135.4,137.9,145$ (4C), 170 (CO); IR (nujol) 3305, 1656, 1421, 1068, 705; Anal. calcd for $\mathrm{C}_{23} \mathrm{H}_{21} \mathrm{NO}_{2}$ : C, 80.44; $\mathrm{H}, 6.16 ; \mathrm{N}, 4.08$. Found: C, 80.09; H, 6.37; N, 3.83; m/z (CI) $344\left[\mathrm{MH}^{+}\right.$, $100 \%]$.

2.3.3. $2-[(1 R)-2-t$ Butoxy-1phenylethyl]-2,3-dihydro- $1 H$ isoindol-1-one (7). The $t$-butyl ether 7 was prepared from 5 following the slightly modified method described by Wright et al. ${ }^{21} 110 \mu \mathrm{L}$ of $\mathrm{H}_{2} \mathrm{SO}_{4}$ concentrated was added to a suspension of magnesium sulfate $(830 \mathrm{mg})$ in dichloromethane $(6 \mathrm{~mL})$, stirred for $15 \mathrm{~min}$ at room temperature under nitrogen. Then 5 (506 $\mathrm{mg}, 2 \mathrm{mmol})$ and anhydrous $t \mathrm{BuOH}\left(950 \mu \mathrm{L}\right.$, in $\left.2 \mathrm{~mL} \mathrm{CH}_{2} \mathrm{Cl}_{2}\right)$ was added. The mixture was stirred 4 days, quenched by addition of $5 \%$ sodium hydrogen carbonate solution $(1.5 \mathrm{~mL})$, extracted twice by $\mathrm{CH}_{2} \mathrm{Cl}_{2}$, dried over $\mathrm{MgSO}_{4}$, filtered and evaporated under vacuum. The residue was purified by flash-column chromatography (eluent ethyl acetate/cyclohexane (1:1) to afford 7 $(400 \mathrm{mg})$ in $65 \%$ yield as a pale yellow powder, which was recrystallized from diisopropyl ether to give clear colorless crystal.

Mp $116^{\circ} \mathrm{C} ;[\alpha]_{\mathrm{D}}=-70\left(c=1.4, \mathrm{CH}_{2} \mathrm{Cl}_{2}\right) ;{ }^{1} \mathrm{H}$ NMR $\delta 1.22(\mathrm{~s}$, $9 \mathrm{H}), 3.96(\mathrm{dd}, J=5.2,9.7 \mathrm{~Hz}, 1 \mathrm{H}), 4.03(\mathrm{dd}, J=6.2,9.7 \mathrm{~Hz}$, $1 \mathrm{H}), 4.18(\mathrm{~d}, J=17.2,1 \mathrm{H}), 4.58(\mathrm{~d}, J=17.2 \mathrm{~Hz}, 1 \mathrm{H}), 5.64(\mathrm{t}$, $J=5.6 \mathrm{~Hz}, 1 \mathrm{H}), 7.22-7.48(\mathrm{~m}, 8 \mathrm{H}), 7.87(\mathrm{~d}, J=7.1 \mathrm{~Hz}, 1 \mathrm{H})$; ${ }^{13} \mathrm{C}$ NMR $\delta 27.3\left(1 \mathrm{CH}_{3}\right), 48\left(1 \mathrm{CH}_{2}\right), 54.8(1 \mathrm{CH}), 62\left(1 \mathrm{CH}_{2}\right)$, 73.3 (1C), 122.5, 123.5, 127.5, 127.6, 127.9, 128.4, 131 $(7 \mathrm{CH}), 132.7,138.3,141.7(3 \mathrm{C}), 168.4(\mathrm{CO})$; IR (nujol) 1682, 1454, 1083, 897; Anal. calcd for $\mathrm{C}_{23} \mathrm{H}_{21} \mathrm{NO}_{2}$ : C, 77.64; H, 7.49; N, 4.53. Found: C, 77.44; H, 7.65; N, $4.40 ; \mathrm{m} / \mathrm{z}(\mathrm{CI}) 310\left[\mathrm{MH}^{+}, 100 \%\right]$.

\section{Acknowledgements}

The authors want to thank Professor S. M. Allin for furnishing NMR spectra of 3-allyl-isoindolinone $\mathbf{6 c}$ and for stimulating discussions. J. P. and J. R thank V. Jenkin and K.
Baghi, two undergraduate students who participated in this work.

\section{References}

1. Chang, Z. L.; Zhu, D.-Y. The Alkaloids; Cordell, G. A., Ed.; Academic: San Diego, 1997; Vol. 49, pp. 29-65.

2. (a) Furusaki, A.; Hashiba, N.; Matsumoto, T.; Hirano, A.; Iwai, Y.; Omura, S. Bull. Chem. Soc. Jpn 1982, 55, 36813685. (b) Weinreb, S. M.; Garigipati, R. S.; Gainor, J. A. Heterocycles 1984, 21, 309-324.

3. Valencia, E.; Weiss, I.; Firdou, S.; Freyer, A. J.; Shamma, M.; Urzua, A.; Fajardo, V. Tetrahedron 1984, 40, 3957-3962.

4. Takahashi, I.; Kawagami, T.; Hirano, E.; Yokota, H.; Kitajiwa, H. Synlett 1996, 353-355.

5. Zhuang, Z.-P.; Kung, M.-P.; Mu, M.; Kung, H. F. J. Med. Chem. 1998, 41, 157-166.

6. De Clercq, E. J. J. Med. Chem. 1995, 38, 2491-2517.

7. Kato, Y.; Takemoto, M.; Achiwa, K. Chem. Pharm. Bull. 1993, 41, 2003-2006.

8. Belliotti, T. R.; Brink, W. A.; Kesten, S. R.; Rubin, J. R.; Wustrow, D. J.; Zoski, K. T.; Whetzel, S. Z.; Corbin, A. E.; Pugsley, T. A.; Heffner, T. G.; Wise, L. D. Med. Chem. Lett. 1998, 8, 1499-1502.

9. Takahashi, I.; Hatanaka, M. Heterocycles 1997, 45, 24752499 and references cited herein.

10. (a) Luzzio, F. A.; Zacherl, D.-A. P. Tetrahedron Lett. 1998 , 39, 2285-2288. (b) Couture, A.; Deniau, E.; Ionescu, D.; Grandclaudon, P. Tetrahedron Lett. 1998, 39, 2319-2320. (c) Guo, Z.; Schultz, A. G. J. Org. Chem. 2001, 66, 21542157. (d) Deniau, E.; Enders, D. Tetrahedron 2001, 57, 25812588.

11. (a) Allin, S. M.; Northfield, C. J.; Page, M. I.; Slawin, A. M. Z. Tetrahedron Lett. 1997, 38, 3627-3630. (b) Allin, S. M.; Northfield, C. J.; Page, M. I.; Slawin, A. M. Z. J. Chem. Soc., Perkin Trans. 1 2000, 1715-1721 and correction: 2001, 3415. (c) Hucher, N.; Decroix, B.; Daïch, A. J. Org. Chem. 2001, 66, 4695-4703.

12. (a) Baussanne, I.; Chiaroni, A.; Riche, C.; Husson, H.-P.; Royer, J. Tetrahedron Lett. 1994, 35, 3931-3934. (b) Baussanne, I.; Travers, C.; Royer, J. Tetrahedron: Asymmetry 1998, 9, 797-804.

13. Thiele, J.; Schneider, J. Ann. Chem. 1909, 369, 287-299.

14. For various examples of the Thiele's condensation and related procedures see: DoMinh, T.; Johnson, A. L.; Senise Jr, P. P. J. Org. Chem. 1977, 42, 4217-4221. Nan'ya, S.; Ishida, H.; Batsugan, Y. J. Hetocycl. Chem. 1994, 31, 1725-1726. Grigg, R.; Gunaratne, H. Q. N.; Shridharan, V. J. Chem. Soc., Chem. Commun. 1985, 1183-1184. Allin, S. M.; Hodkinson, C. C.; Taj, N. Synlett 1996, 781-782. Kametani, T.; Kigasawa, K.; Ishimura, H.; Haga, S.; Shirayama, K. J. Heterocycl. Chem. 1978, 15, 369-375. Katritzki, A. R.; Rachwal, S.; Hitchings, G. J. Tetrahedron 1991, 47, 2683-2732.

15. Fains, O.; Vernon, J. M. Tetrahedron Lett. 1997, 38, 82658266.

16. The spectral data for this compound $\left[\left(3 R, 1^{\prime} R\right)-\mathbf{6 c}\right]$ was found identical from that one described by Allin et al. in Ref. 11b who assigned a $\left(3 S, 1^{\prime} R\right)$ configuration. In this Perkin Trans-1 publication, the authors probably inverted the spectral data of the two epimers obtained after separation (only one epimer is described).

17. Ottwinosky, Z.; Minor, W. Method in Enzymology; Carter Jr, 
C. W., Sweet, L. M., Eds.; Academic: San Diego, 1997; Vol. 276, pp. 307-326.

18. Sheldrick, G. M. SHELXLS 97: program for solution of crystal structures; University of Göttingen: Germany, 1990.

19. Sheldrick, G. M.; Schneider, T. R. SHELXL: High Resolution Refinement. Methods in Enzymology; Carter Jr, C. W., Sweet,
L. M., Eds.; Academic: San Diego, 1997; Vol. 277, pp. 319_ 343.

20. Johnson, C. K. ORTEP: a thermal ellipsoid plotting program; Oak Ridge National Laboratories: Oak Rid, TN, 1976.

21. Wright, S. W.; Hageman, D. L.; Wright, A. S.; McClure, L. D. Tetrahedron Lett. 1997, 38, 7345-7348. 